\title{
Growing Teratoma Syndrome
}

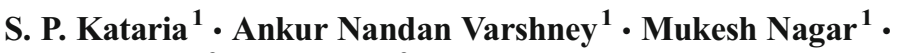 \\ A. K. Mandal ${ }^{2}$ - Vidya Jha ${ }^{2}$
}

Received: 19 July 2016 / Accepted: 18 October 2016/Published online: 27 October 2016

(C) Indian Association of Surgical Oncology 2016

\begin{abstract}
Growing teratoma syndrome, a disease characterized by presence of benign metastasis increasing in size and number after chemotherapy, is infrequent occurrence. Being unfamiliar with the disease entity, many oncologists misinterpret it as disease progression. Though the exact etio-pathognesis of the disease is still unidentified, but clinical characteristics are well defined. Being a chemo and radio-resistant disease, surgery offers only cure. We present a case of ovarian immature teratoma, who after chemotherapy presented with increased tumor size. Resected specimen confirms the diagnosis of mature teratoma leading to recognition of GTS. Surgery resulted in cure.
\end{abstract}

Keywords Growing teratoma syndrome · Teratoma $\cdot$ Benign metastasis $\cdot$ Chemotherapeutic retroconversion

\section{Introduction}

Growing teratoma syndrome (GTS) is a rare disease occurring in patients with non-seminomatous germ cell tumors which is characterized by metastases of benign origin in presence of normal tumor markers either during or after completion of chemotherapy. Concept of GTS was described by Logothetis in 1982 in six patients ( 5 testicular NSGCT and 1 ovarian immature teratoma) [1]. He coined the term GTS and narrated

Ankur Nandan Varshney

drankurnvarshney@gmail.com

1 Department of Medical Oncology, Vardhman Mahavir Medical College and Safdurjung Hospital, New Delhi 110029, India

2 Department of Pathology, Vardhman Mahavir Medical College and Safdurjung Hospital, New Delhi 110029, India
Logothetis criteria to diagnose this rare entity. Since then, medical literature has been endorsed with many case reports and case series adding relevant knowledge regarding disease. Still being rare entity, awareness regarding GTS is not common. This leads to delay in diagnosis and surgical intervention which not only leads to increase in complications but increased financial burden also. We hereby report a case of GTS arising in a 10-year-old female after chemotherapy for an ovarian teratoma. A review of existing scientific literature is done to through light on diagnosis and management of disease.

\section{Case Report}

A 10-year-old female presented to us with gradual distension of abdomen and dull aching, diffuse pain over whole abdomen without any aggravating and relieving factors since last 2 months. She has not achieved menarche yet and family history was non-contributory. Contrast enhanced CT (CECT) revealed a large heterogeneously enhancing predominantly solid mass with multiple septae and cysts, with specs of calcification arising from pelvic cavity, not separated from ovaries (Fig. 1A). Serological test displayed Alpha-feto protein $=303 \mathrm{IU} / \mathrm{ml}$ (increased), Beta $\mathrm{HCG}=2.5 \mathrm{mIU} / \mathrm{ml}$ (WNL), $\mathrm{LDH}=190(\mathrm{WNL})$, and CA-125 = $23.4 \mathrm{U} / \mathrm{ml}$. Biopsy of ovarian mass displayed immature teratoma with immature neural component including rosettes, primitive neural tubules (Fig. 2A). Thus, she was given 4 cycles of BEP regime every 21 days (Etoposide $=100 \mathrm{mg} / \mathrm{m} 2 \mathrm{D} 1-5$, Cisplatin $=20 \mathrm{mg} / \mathrm{m} 2$ D1-5, Bleomycin =30 IU D1, 8, and 15). Post-chemotherapy CECT revealed large heterogeneous ovarian mass with calcification with involvement of rectosigmoid, iliac vessels, psoas muscles, anterior abdominal wall, and large sub-phrenic deposits suggestive of increase in size of mass as compared to 


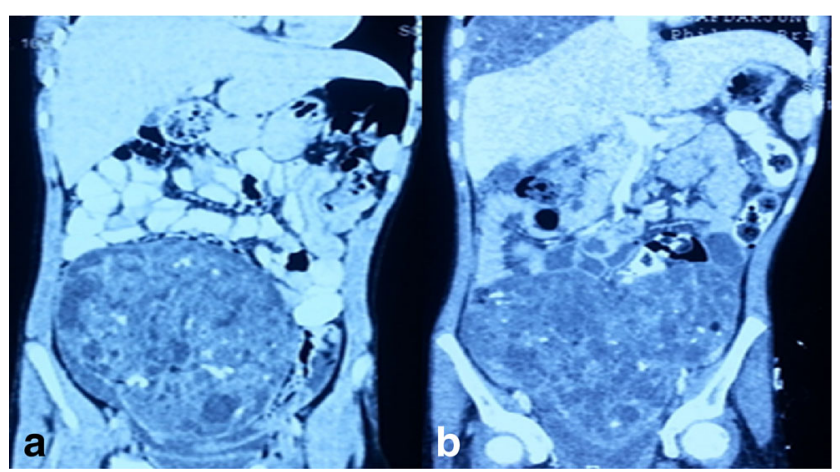

Fig. 1 a Showing CECT pre-chemo revealing an ovarian mass predominantly solid with multiple septae and cysts, with specs of calcification while b shows post-chemo CECT showing ovarian mass with calcification with involvement of rectosigmoid, large sub-phrenic deposits suggestive of increase in size of mass as compared to previous scan

previous scan (Fig. 1B). Post-chemo biomarkers were Alphafeto protein $=4.9 \mathrm{IU} / \mathrm{ml}$ (normal), Beta $\mathrm{HCG}=1.6 \mathrm{mIU} / \mathrm{ml}$ (normal), and LDH $=190$ (normal). These evidences guide us to suspicion of GTS. Patient was referred for cyto-reductive surgery. Biopsy of resected specimen showed mature cystic teratoma showing maturation brain tissue, bone, cartilage, fat, and columnar epithelium breech suggestive of mature cystic teratoma with capsular breech and glial implants. This validated the diagnosis of growing teratoma syndrome (Fig. 2B). Patient is in regular follow-up and serum bio-markers and CECT after 6 months were within normal limits.

\section{Discussion}

Increase in size of tumor mass or number of lesions after or during chemotherapy is considered as treatment failure. This is often a widespread clinical practice. Absence of knowledge regarding GTS often leads to it. Hereby we present a review of existing medical literature.

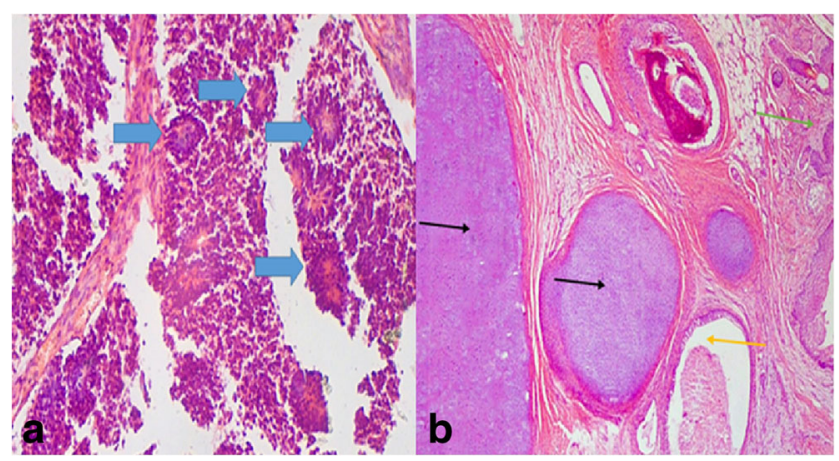

Fig. 2 a Displaying primitive neuroectodermal tissue. Blue arrows show formation of rossettes. b Showed mature teratoma. Black arrow shows mature cartilage. Yellow arrow demonstrated glands lined by columnar epithelium and green arrows shows keratinized stratified squamous epithelium with hair follicle

\section{Annals of GTS}

The disease was first identified in 1969 and reported by DW Smithers from Royal Cancer Hospital, London as benign maturation occurring in five patients of primary testicular germ cell neoplasm with metastatic sites demonstrating welldifferentiated benign elements [2]. Four years later, Willis reported similar occurrence in patients of embryonal testicular carcinoma after completion of treatment. Dees reported a case occurring after 8 years of treatment [3]. In 1977, Merrin et al. documented this phenomenon in seven patients of testicular carcinoma [4]. In similar year, DiSaia et al. coined the term "Chemotherapeutic Retroconversion" for this disease in patient of ovarian immature teratoma [5]. The first incidence statistics of disease as $2 \%$ was reported by Hong et al. from MSK cancer centre with 12 cases among 600 patients of testicular germ cell carcinoma [6]. Carr et al. in 1981 threw light on role of surgical resection in four patients with testicular germ cell tumor [7]. After 13 years of first report, Logothetis and colleagues from MD Anderson institute coined the " Growing Teratoma Syndrome " and described the disease entity as known to us today [1]. Until 2004, GTS was considered as synonym with chemotherapeutic- retroconversion (CT) when Amasalem et al. challenged it [8]. He asserted that in $\mathrm{CT}$, there is only conversion of an immature teratoma component into a mature teratoma as a result of chemotherapy/ chemo-radiation and includes non-expanding metastatic disesase. On the other hand, GTS includes expansion of benign masses which includes increase in size of initial lesions as well as appearance of new lesions. It was later supported by Djordevic B et al. [9]. Since then, term "Chemotherapeutic Retroconversion" is discarded.

\section{Etiology and Pathogenesis}

The exact etiology of disease is still unclear. No single genetic or environment factor has been implicated with GTS. As GTS have been reported with every chemotherapeutic agent that are used in treatment of germ cell tumor (Bleomycin, Etoposide, Cisplatin, Methotrexate, Actinomycin D, Cyclophosphamide), no drug is considered to have been associated with increased incidence of GTS [10].

Four hypotheses have been formulated to advocate the development of GTS. The most commonly accepted hypothesis by Andre et al. suggests that chemotherapy may selectively inactivate the immature component and prolongs course of disease which allows benign components to grow further [11]. A second hypothesis proposed chemotherapy may change cell behavior from a totipotent malignant germ cell tumor towards a benign teratoma $[4,10]$. Hong et al. performed an experimental terato-carcinoma mouse model and suggested a tendency of inherent and spontaneous of 
malignant cells into benign tissues [6]. Willis also proposed a theory of unrecognized metastasis of mature teratoma from primary immature teratoma [3]. However, the exact mechanism is still unclear.

On pathological examination, GTS consists of both solid and cystic changes. It may contain sebaceous secretions, tooth, nail, and hair follicles usually a feature of mature teratoma elements. Microscopically, there is presence of cartilage with ciliated respiratory type epithelium, enteric epithelium, or neurogenic tissue in background of undifferentiated mesenchymal spindle cells [10].

Despite being an unpredictable disease entity, there are conditions which can predict the development of GTS in a patient with germ cell tumor. Andre et al. suggested that existence of mature teratoma component in primary tumor, insufficient initial surgery, and metastatic disease not responding to chemotherapy lead to increased risk of GTS [11]. Zagame et al. advocated the involvement of primary peritoneum and presence of neuro-ectodermal tumor are important risk factors for development of GTS [12].

\section{Diagnosis}

Diagnosis of GTS remains a significant challenge to oncologists owing to the rarity of disease. However, an early diagnosis can prevent patient from expensive investigations, chemo-radiotherapy, and extensive surgery. The diagnosis is established by Logothetis criteria [1]. These include the following: (1) normalization of serum markers, (2) increasing size or number or both of lesions on serial imaging either during chemotherapy or after completion of chemotherapy, and (3) exclusive presence of mature teratoma components in resected specimen in a patient with known history of NSGCT.

\section{Clinical Characteristics}

There is a wide variation in prevalence of the disease between 1.9 to 7.6 as per various studies reported $[1,13]$. Though the disease is well described with both testicular and ovarian germ cell neoplasm, males are at increased risk of GTS as compare to females [12].Three cases of GTS after chemotherapy for primary intra-cranial NSGCT have been reported [14]. GTS can present at any time after chemotherapy with early reports of after 2 cycles of chemotherapy and late reports of occurrence after 12 years of chemotherapy [15]. The maximum occurrence usually occurs within 24 months after completion of chemotherapy, and after 24 months, occurrence of GTS is quite rare [9]. Almost every organ site involvement has been reported with retro-peritoneum being the most common site. Lung, mediastinum, lymph nodes, forearm, mesentery, and liver are other common sites [16]. Usually distant relapses are more common after testicular tumors [1]. An unusual presentation associated with ovary associated GTS is Gliomatosis Peritonei characterized by presence of mature glial tissue in the peritoneum [17].

The classical feature of GTS is normalization of serum biomarkers (beta-HCG, LDH, alpha-fetoprotein) after completion of chemotherapy [1]. Persistently elevated markers suggest presence of active immature carcinomatous component, and GCT is ruled out. However, non-NSGCT causes such as hepatocellular carcinoma must be ruled out [18]. One case report of ovarian NSGCT with spuriously elevated alpha-fetoprotein has been reported but the marker was normalized after surgery [19].

GTS is usually followed by computed tomographic (CTscan). No-specific radiological feature or any growth size/rate has been associated with GTS. However, certain radiological features as increased number of lesions with increased cystic changes, punctuate or curvilinear calcifications, and better circumscribed margins are more common in patients of GTS [20]. The maximum diameter of GTS mass reported is $25 \mathrm{~cm}$. Growth rates vary widely among patients with a median increase in diameter of $0.7 \mathrm{~cm}$ per month and median growth of volume of $12.9 \mathrm{ml} / \mathrm{month}$ [21]. Any patient of NSGCT with a rapid increase in tumor growth rate after chemotherapy in presence of normal serum markers should alarm the clinician with GTS. Recently, some studies have also quoted the role of fluoro-deoxyglucose Positron Emission Tomography (FDGPET scan) in patients with GTS. FDG activity suggests active viable tumor where as non-FDG avidity signifies tumor necrosis or mature teratoma [22]. Hariprasad et al. assessed PET and pathological findings in GTS and suggested that PET cannot differentiate between GTS and recurrence of malignant component [23]. Till now, PET scan is not mandatory to establish the diagnosis of GTS but can be useful for detection of disseminated disease.

\section{Treatment}

Contrary to NSGCT which is highly chemo-sensitive disease, GTS is a chemo and radio-resistant tumor. Surgical excision of tumor remains the cornerstone of treatment but chemotherapy can be of help to reduce size of deposits making them feasible for surgery [1].

Surgical intervention should be done as early as possible. Both laparotomy and laparoscopic approach are advisable to reduce tumor bulk. Laparoscopy is associated with less postoperative complications but port-site recurrence is well documented [24]. Late surgery may lead to increased tumor size leading to mechanical compression of vital organs leading renal dysfunction because of ureteral compression, bowel ischemia, and biliary obstruction. Also, increased tumor burden 
is associated with increased post-operative complications and increase risk of recurrence due to tumor rupture [25]. Incomplete resection leads to increased chances of recurrence (50-83\%) while complete resection leads to recurrence of 0 $4 \%[11,21]$. Thus, complete resection is mandatory. Surgical intervention also reduces the risk of degeneration of mature teratoma into immature germ cell tumor [26].

In the last decade, role of chemotherapy has increased especially in patients where disease is unresectable/inoperable. Rustin et al. [27] used interferon in patients with unresectable disease but it leads only to a minor reduction in size, and disease recurred later as soon as treatment was stopped. Mego et al. introduced bevacizumab, in patients with unresectable disease [28]. Patient responded with significant reduction in size of tumor but it again showed progression as treatment was terminated. Vaughn et al. demonstrated presence of Cyclin-dependent kinase 4/6 on mature teratoma component and PD0332991, a CD4/6 inhibitor was given to three patients [29]. One had shown partial response and other two had stable disease with its continued use.

Thus, surgery remains gold standard of treatment and a complete resection must be made.

\section{Follow up and Prognosis}

Prognosis of completely resected GTS is considered as good surgery if often curative. A 5-year survival rate is considered to be $89-90 \%$ [10]. A $10 \%$ mortality is accounted by postoperative complications and development of secondary cancers. Approximately 3-5\% of GTS lesions undergo transformation to adenocarcinoma, squamous cell carcinoma, sarcoma, and carcinoids [11]. There is also increased risk of chemotherapy induced leukemia.

No single test is considered as optimal test for follow up of patients with GTS. Thus, radiological test are combined with serological investigations. Radiological test as CT scan are useful for morphological assessment of disease and can easily assess increase in size of mass and new lesion while serological test (LDH, beta HCG, and alpha-fetoprotein) are helpful in detecting early transformation to immature component or presence of initial immature component [22]. As late recurrences are known to occur, patients with risk factors for recurrence must be followed up to 10 years.

\section{Conclusion}

Growing Teratoma Syndrome is a rare clinical entity. It should be suspected in patients of NSGCT who had increased tumor size/number of lesion after chemotherapy in presence of normal serum markers. Histological confirmation of benign mature teratoma in resected tissue specimen is compulsory for diagnosis. An optimal cytoreduction without any gross residual disease is associated with favorable prognosis. An early surgical intervention prevents complication associated with increased tumor mass peri-operative complications and future risk of malignant transformation. Regular follow up is mandatory.

\section{Compliance with Ethical Standards}

Conflict of Interest The authors declare that they have no conflict of interest.

Source of Funding None

\section{References}

1. Logothetis CJ, Logothetis CJ, Samuels ML, Trindade A, Johnson DE (1982) The growing teratoma syndrome. Cancer 50:1629-1635

2. Smithers DW (1969) Maturation in human tumours. Lancet 2:949-952

3. Willis GW, Hajdu SI (1973) Histologically benign teratoid metastasis of testicular embryonal carcinoma. Am J Clin Pathol 59:338-343

4. Merrin C, Baumbgartner G, Wajsman Z (1975) Benign transformation of testicular carcinoma by chemotherapy. Lancet 1:43-44

5. DiSaia PJ, Saltz A, Kagan AR, Morrow CP (1977) Chemotherapeutic retroconversion of immature teratoma of the ovary. Obstet Gynecol 49:346-350

6. Hong WK, Wittes RE, Hajdu ST, Cvitkovic E, Whitmore WF, Golbey RB (1977) The evolution of mature teratoma from malignant testicular tumors. Cancer 40:2987-2992

7. Carr BI, Gilchrist KW, Carbone PP (1981) The variable transformation in metastases from testicular germ cell tumors: the need for selective biopsy. J Urol 126:52-54

8. Amsalem H, Nadjari M, Prus D, Hiller N, Benshushan A (2004) Growing teratoma syndrome vs. chemotherapeutic retroconversion: case report and review of literature. Gynecol Oncol 92:357-360

9. Djordjevic B, Euscher ED, Malpica A (2007) Growing teratoma syndrome of the ovary: review of literature and first report of a carcinoid tumor arising in a growing teratoma of the ovary. Am J Surg Pathol 31:1913-1918

10. Gorbatiy V, Spiess PE, Pisters LL (2009) The growing teratoma syndrome: current review of the literature. Indian J Urol 25:186-189

11. Andre F, Fizazi K, Culine S, Droz J, Taupin P, Lhomme C et al (2000) The growing teratoma syndrome: results of therapy and long-term follow-up of 33 patients. Eur J Cancer 36:1389-1394

12. Zagame L, Pautier P, Duvillard P et al (2006) Growing teratoma syndrome after ovarian germ cell tumors. Obstet Gynecol 108:509-514

13. Jeffery GM, Theaker JM, Lee AH, Blaquiere RM, Smart CJ, Mead GM (1991) The growing teratoma syndrome. Br J Urol 67:195-202

14. O'Callaghan AM, Katapodis O, Ellison DW, Theaker JM, Mead GM (1997) The growing teratoma syndrome in a nongerminomatous germ cell tumor of the pineal gland. Cancer 80:942-947

15. Dees JE (1973) Metastatic embryonal cell carcinoma of testis: an apparent 8-year cure. J Urol 110:90-92

16. Maroto P, Tabernero JM, Villavicencio H, Mesla R, Marcuello E, Sole-Balcells FJ et al (1997) Growing teratoma syndrome: experience of a single institution. Eur Urol 32:305-309

17. Bentivegna E, Gonthier C, Uzan C et al (2015) Gliomatosis peritonei: a particular entity with specific outcomes within the growing teratoma syndrome. Int J Gynaecol Cancer 25:244-249 
18. Spiess PE, Tannir NM, Tu SM, Brown GA, Liu P, Kamat AM et al (2007) Viable germ cell tumor at postchemotherapy retroperitoneal lymph node dissection: can we predict patients at risk of disease progression? Cancer 110:2700-2708

19. Pendlebury A, Rischin D, Jenkin KI, Toner GC, Grant P (2015) Ovarian growing teratoma syndrome with spuriously elevated alpha-fetoprotein. J Clin Onco 33(24):e-99-e100

20. Nimkin K, Gupta P, McCauley R, Gilchrist BF, Lessin MS (2004) The growing teratoma syndrome. Pediatr Radiol 34:259-262

21. Spiess PE, Kassouf W, Brown GA, Kamat AM, Liu P, Gomez JA et al (2007) Surgical management of growing teratoma syndrome: the M. D. Anderson cancer center experience. J Urol 177:1330-1334

22. Aide N, Comoz F, Savin E (2007) Enlarging residual mass after treatment of a nonseminomatous germ cell tumor: growing teratoma syndrome or cancer recurrence? J Clin Oncol 25:4494-4496

23. Hariprasad R, Kumar L, Janga D et al (2008) Growing teratoma syndrome of ovary. Int J Clin Oncol 13:83-87
24. Sengar AR, Kulkarni JN (2010) Growing teratoma syndrome in a post laparoscopic excision of ovarian immature teratoma. J Gynaecol Oncol 21:129-131

25. Tangjitgamol S, Manusirivithaya S, Leelahakorn S, Thawaramara T, Suekwatana P, Sheanakul C (2006) The growing teratoma syndrome: a case report and a review of literature. Int J Gynecol Cancer 16:384-390

26. Kattan J, Droz JP, Culine S, Duvillard P, Theiellet A, Peillon C (1993) The growing teratoma syndrome: a woman with nonseminomatous germ cell tumor of the ovary. Gynecol Oncol 49:395-399

27. Rustin GJS, Kaye SB, Williams CJ, Newlands ES, Bagshawe KD, Toy JL (1982) Response of differentiated but not anaplastic teratoma to interferon. Br J Cancer 50:611-616

28. Mego M, Reckova M, Sycova-Mila Z, Obertova J, Brozmanova K, Salek T, Mardiak J (2007) Bevacizumab in a growing teratoma syndrome. Case report Ann Oncol 18:962-963

29. Vaughn DJ, Flaherty K, Lal P et al (2009) Treatment of growing teratoma syndrome. N Engl J Med 360(4):423-424 